Check for updates

London

Cite this as: $B M J 2020 ; 371: \mathrm{m} 3926$

http://dx.doi.org/10.1136/bmi.m3926

Published: 08 October 2020

\section{BMJ Awards 2020: NHS chief hails clinical leaders as winners are announced}

\author{
Matthew Limb
}

The NHS was never a "covid only" service even at the height of the coronavirus pandemic, NHS England's chief executive, Simon Stevens, insisted at the BMJ Awards ceremony last night.

Stevens was speaking at a virtual presentation ceremony on Wednesday 7 October, where the list of winners was announced (box). He said that 2020 would probably be the "defining year" in the NHS's history, given how it had been tested and how covid-19 had had an impact on other services. But he said that NHS staff had responded "impressively, with conviction and with agility,” saving many lives.

They were now gearing up to counter a further increase in the prevalence of covid-19 alongside restarting a "wider range" of services, he said.

Stevens paid tribute to the winning and shortlisted teams and clinicians across the NHS. He said, "If the BMJ Awards represent anything, they represent a bottling of that clinical, can-do attitude, refracted through the lens of what patients themselves are telling us they need from services."

Stevens said the NHS had looked after 108 ooo people needing specialist inpatient care with coronavirus since the pandemic began. "Even at the peak of hospital admissions in critical care, for every coronavirus patient we were looking after in hospital we were looking after two other non-covid patients," he said.

"So although there has undoubtedly been a short term impact on many other services, it's just not true that the NHS was ever a covid service only."

Stevens said other health services across the world had also been severely tested, and it was right that there would continue to be a "lively debate" about many aspects of the UK's response and opportunities to learn from international experience. "As we now look out over the next six months and beyond, we have clearly got to combine readiness for a response to further coronavirus prevalence and the restart of a far wider range of NHS services," he said.

"That will only happen not just by doing more of what we used to do but by doing some things differently. What that 'differently' looks like ultimately will depend on the innovation and the freedom to get on with it that clinical teams and frontline services across the NHS have."

Fiona Godlee, The BMJ's editor in chief, who hosted the online awards, said it was more important than ever to recognise the work of healthcare professionals throughout the country. "We have seen the immense pressures and the increased demand for your expertise. The response to covid-19, the teamwork, commitment, and resilience you have shown, has been extraordinary," she said.

She said the awards continued the nation's appreciation for healthcare and key workers, as shown earlier in the pandemic by the Clap for Carers and children's many drawings of rainbows for the NHS.

\section{The BMJ Awards 2020: Full list of winners}

\section{Anaesthesia and Perioperative Medicine Team of the} Year

Winner: Manchester University NHS Foundation Trust, for Improving Tracheostomy Care

Description: A multidisciplinary quality improvement (QI) project rolled out to 20 hospitals in England. The programme standardised care for patients with tracheostomies and has reduced the number of harmful incidents.

Judges' verdict: “Ambitious and impressive ... with great patient engagement. It's already delivered excellent outcomes for patients in a safety critical area of practice. A worthy winner."

Highly commended: Two projects: PREP-WELL, South Tees Hospitals NHS Foundation Trust, and QEH London, by the NELA Team at Lewisham and Greenwich NHS Trust Cancer Care Team of the Year

Winner: Oxford University Hospitals NHS Foundation Trust and Oxfordshire CCG, for the SCAN Pathway Description: Designed for patients with "low risk but not no risk" cancer symptoms, it refers patients directly from general practices for $\mathrm{CT}$ scanning and onward referral to the appropriate consultant. The pathway has achieved a higher pick-up rate of cancer diagnoses than the conventional two week wait cancer pathway.

Judges' verdict: "An outstanding project with an authentic and thoughtful approach, a great step forward."

\section{Clinical Leadership Team of the Year}

Winner: Public Health Wales and all health boards in Wales, for the Hepatitis C Elimination Wales project Description: This improved access to testing and treatment though a national network. The team developed national treatment guidelines that eliminated postcode prescribing and significantly improved cure rates.

Judges' verdict: “The judges were unanimous and strongly felt that the breadth of collaboration shown was phenomenal and what they have achieved is breath taking."

Highly commended: SPELTIP on the Emergency Floor, University Hospitals of Leicester NHS Trust

\section{Dermatology Team of the Year}

Winner: Chelsea and Westminster Hospital NHS Foundation Trust, for its Teledermatology Cancer Clinic Description: The trust changed its pathway for patients with suspected skin cancer who are referred by their GP for an appointment with a medical photographer. A consultant dermatologist reviews the images, and appropriate management is initiated. This has seen a third of patients discharged without a face-to-face 
clinician appointment and an increase in skin cancer diagnoses. Judges' verdict: “Impressive. The service has seen several thousand patients since 2017. It has an excellent safety record with an increase in the pick-up rate for certain cancers despite fewer biopsies."

\section{Diagnostics Team of the Year}

Winner: Healthy.io and Modality Partnership, a partnership of GP practices, for Digital Home Albumin Screening

Description: They showed the benefits of a low cost, smartphone based home albumin testing kit for patients with type 2 diabetes. Tests on nearly 500 patients were evaluated by 10 modality GP practices in Hull, Airedale, Wharfedale, and Craven. An abnormal albumin:creatinine ratio, suggestive of previously undiagnosed chronic kidney disease, was indicated in $11 \%$ of patients.

Judges' verdict: “The innovative solution has a large scale impact at a relatively low cost. It benefits a large patient population with exciting potential for future development."

Highly commended: Implantable Loop Recorder, Southern HSC Trust Digital Innovation Team of the Year

Winner: Explain My Procedure and Barts Health NHS Trust, for its Animation Supported Consent project

Description: The team radically improved patients' understanding of clinical procedures and the trade-offs between benefit and risks by creating innovative videos with simple explanations in different languages.

Judges' verdict: "This superb entry identified an important problem and came up with an innovative, stand-out solution."

Highly commended: Digital Postnatal Suite @ChelwestFT

Environmental Sustainability and Climate Action in Healthcare Team of the Year

Winner: University Hospital of North Midlands, for its Saving Lives with Solar project

Description: It used savings from clean energy investments, such as solar panels, to tackle fuel poverty related health inequality, in partnership with other organisations.

Judges' verdict: “An example of a collaboration that isn't easy to achieve. As well as improving the quality of life of people in the local community, it sets an excellent example for other NHS trusts to replicate similar projects."

Highly commended: One Health Breakthrough Partnership, NHS Highland Innovation in Quality Improvement Team of the Year

Winner: Western Health and Social Care Trust in Northern Ireland, for its Gestational Diabetes Pathway

Description: The new pathway has improved the flow of appointments and cut waiting times. The introduction of virtual video clinics, supported by cloud based glucose monitoring technology, reduced the number of face-to-face specialist appointments and cut travelling times for patients. Judges' verdict: “A great project which truly encompasses what QI should entail-a great multidisciplinary approach and team focused."

Highly commended: Beechcroft PRN Project, Belfast Trust

\section{Mental Health Team of the Year}

Winner: Cornwall Partnership NHS Foundation Trust, for Local Radio and Mental Wellbeing

Description: This features a regular and long running local radio phone-in programme on mental health, which has input from a psychiatrist and a non-medical or patient expert. The programme has helped to reduce stigma and discrimination faced by people with mental health difficulties and provides valuable public education.

Judges' verdict: “Imaginative and innovative. A sustained effort to support people in an area with high rates of suicide, involving experts by experience and a significant investment of time by clinicians."

Highly commended: StayingSafe.net, 4 Mental Health

\section{Primary Care Team of the Year}

Winner: Healthy Hyde Team, for inspirational work in Greater Manchester that gave patients in care homes a bigger say in how their care is managed.
Description: Compassionate advanced care plans helped to reduce hospital admissions and attendances at A\&E.

Judges' verdict: "Impressed that such a personal and individualised approach was taken throughout the project."

Highly commended: Community Connectors, Frome Medical Practice Respiratory Team of the Year

Winner: The respiratory infection team at University Hospitals of Derby and Burton NHS Foundation Trust

Description: The team's project improved outcomes for people with community acquired pneumonia, reduced hospital admissions, readmissions, and length of stay, and delivered cost savings.

Judges' verdict: "This excellent project made a substantial difference to patient centred outcomes and experience."

\section{Stroke and Cardiovascular Team of the Year}

Winner: Royal Cornwall Hospitals NHS Trust and University of Exeter for Rehabilitation

Enablement in Chronic Heart Failure (REACH HF)

Description: The cardiac rehabilitation and self-management programme, which features home visits by cardiac nurses and other support, has helped to improve patients' quality of life and is being rolled out and evaluated by other NHS trusts.

Judges' verdict: "Founded on research and patient involvement, this is an impressive example of excellent teamwork producing a real world solution."

Highly commended: LUPA Project, Guy's and St Thomas' NHS Foundation Trust

\section{Women's Health Team of the Year}

Winner: Basildon and Thurrock Hospitals NHS Foundation Trust, for its GooD Pregnancy Network

Description: The team improved the care and experiences of mothers with gestational diabetes by raising awareness and empowering patients, showing excellent leadership and dedication.

Judges' verdict: "A very innovative project with minimal resources that demonstrated a positive and resourceful approach to problem solving." Highly commended: New testing for Pre-eclampsia, Guy's and St Thomas' NHS Foundation Trust

\section{Workforce and Wellbeing Team of the Year}

Winner: A collaboration by three bodies, the Association of Anaesthetists, the Royal College of Anaesthetists, and the Faculty of Intensive Care Medicine

Description: Their Joint Fatigue Working Group tackled the damaging effects of night working among NHS staff. It built on peer reviewed surveys and working groups to deliver highly positive results.

Judges' verdict: “Highly impressive outcomes. This is a great example of collaborative working and pushing an extremely important issue higher on everyone's agendas."

Highly commended: Emergency Department Workforce Wellbeing Strategy, Royal London Hospital 